\title{
Ламкова М.K.
}

Научный руководитель: Гривенная Н.В.

Возможности использования облачных сервисов Google

\section{на уроках информатики в средней школе}

\section{Аннотация}

В работе исследуется вопрос использования современных технологий в процессе обучения. Авторами описываются некоторые функции облачных сервисов GoogleDocs и способы их реализации на различных этапах уроков информатики.

К Ключевые слова: информатика, Google, облачные сервисы, GoogleForms, GoogleJamboard, GoogleDocs.

\section{Lamkova M.K. in High School Computer Science Classes}

\section{Abstract}

The article examines the issue of usage of contemporary technologies in education. The authors describe some of the functions of GoogleDocs cloud services and how to implement them at various stages of computer science lessons.

Keywords: IT, Google, computer science, cloud services, GoogleForms, GoogleJamboard, GoogleDocs.

$\mathrm{B}$ настоящее время перед школой стоит задача формирования личности, готовой жить в стремительно меняющемся мире, в высокоразвитой информационной среде, готовой к постоянному саморазвитию и возможности получения дальнейшего образования, в том числе и с использованием современных информационных технологий обучения.

Одной из новых информационных технологий, с которой современным педагогам необходимо познакомиться и активно использовать в учебно-воспитательном процессе, являются облачные технологии.

Облачные технологии представляют собой технологии обработки данных, где компьютерные ресурсы представляются пользователю в виде онлайн сервисов.

Использование облачных технологий на уроках информатики будет способствовать формированию информационно-коммуникационной компетентности учащихся, их успешной социальной адаптации, взаимоотношению со сверстниками, способствовать саморазвитию и самообразованию, а также планировать свою учебную деятельность.
Различают 3 основных вида облачных технологий: программное обеспечение как сервис (SaaS); платформа как сервис (PaaS); инфраструктура как сервис (IaaS).

Сервисы Web 2.0 (облачные сервисы) в последнее время занимают лидирующие позиции в Интернет-технологиях и позволяют сделать уроки более эффективными, разнообразными и познавательными для учащихся, а, следовательно, значительно повышается интерес к обучению [1]. С их помощью современные школьники могут гораздо эффективнее реализовать себя социально, работать индивидуально, каждый в своем темпе, а учителя - применять творческие подходы к обучению, сделать урок по-настоящему продуктивным, процесс учебы интересным.

Одним из популярных облачных сервисов в сфере образования являются сервисы Google. Google разрабатывает и предоставляет множество приложений и сервисов, доступ к которым возможен в окне любого браузера, также предоставляют широкий круг возможностей как для учащихся, так и для учителей.

Использование информационных ресурсов и средств коммуникации «облачных» технологий сервиса GoogleDocs 
на уроках информатики даёт возможность применения системно-деятельностного подхода в обучении.

Технология работы в мини-группах с использованием «облачного» сервиса GoogleDocs может быть использована для обучения учащихся 5-9 классов [2].

Рассмотрим возможности использования некоторых облачных сервисов на уроках информатики. Например, создадим опрос в GoogleForms по теме «Основные компоненты компьютера», данная тема входит в состав календарно-тематического планирования по информатике 7 класса под редакцией Л.Л. Босовой.

Цель создания формы - провести тестирование по пройденной теме. B GoogleForms можно использовать различные типы вопросов, для каждого вопроса назначается определённое количество балов.

После создания теста учитель может поделиться ссылкой или приглашением, что будет очень удобно при дистанционном обучении. Благодаря просмотру ответов, учитель может проанализировать освоение пройденного материала, так как выводится статистика вопросов, на которые часто даются неправильные ответы. Имеется возможность просмотра ответов как всего класса, так и отдельно каждого ученика.

Подсчет количества баллов ведется автоматически. На экран учащегося выводится итоговая оценка, количество допущенных ошибок, что дает возможность обучающемуся провести самопроверку. Данную форму можно применить, например, на этапе «актуализация знаний» или на этапе «самостоятельная работа и проверка по эталону».

Далее рассмотрим еще одну возможность облачных сервисов Google - GoogleJamboard. GoogleJamboard это интерактивная онлайн-доска, позволяющая дистанционно работать в режиме реального времени большому количеству участников. В ней можно совместно с коллегами или обучающимися создавать контент, печатать, писать и редактировать тексты, рисовать, загружать изображения и работать на этих изображениях.

Необходимым условием использования GoogleJamboard является наличие аккаунта в Google и у учителя, и у ученика. Если его нет, необходимо обязательно зарегистрироваться. После регистрации сервис становится доступным.

GoogleJamboard удобно использовать для дистанционной работы как индивидуально с каждым учеником, так и при групповой работе с классом.

Теперь рассмотрим презентации Google. «Google Презентации» - бесплатное онлайн-приложение, созданное корпорацией Google и предназначенное для разработки, редактирования и хранения презентации. Презентации,

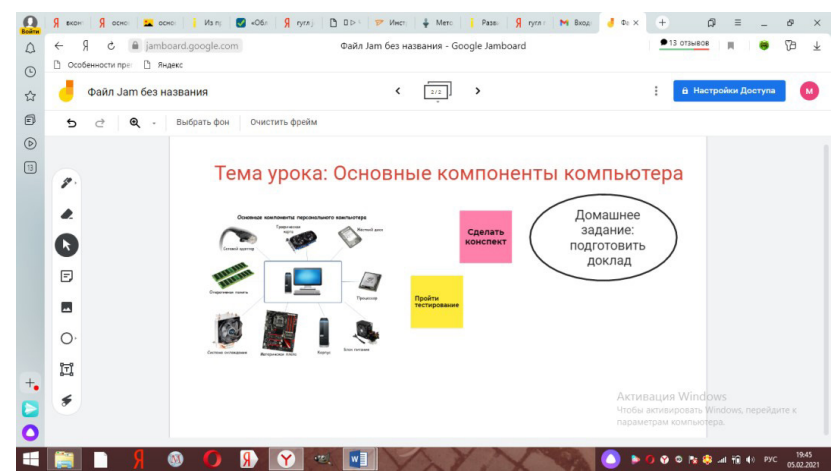

Рис. 1. Интерфейс GoogleJamboard создаваемые индивидуально или в совместном режиме, позволяют визуализировать информацию, сэкономить время на уроках при изучении некоторых тем, позволяют узнать что-то новое по предмету, учат работать в группе [3; с. 127].

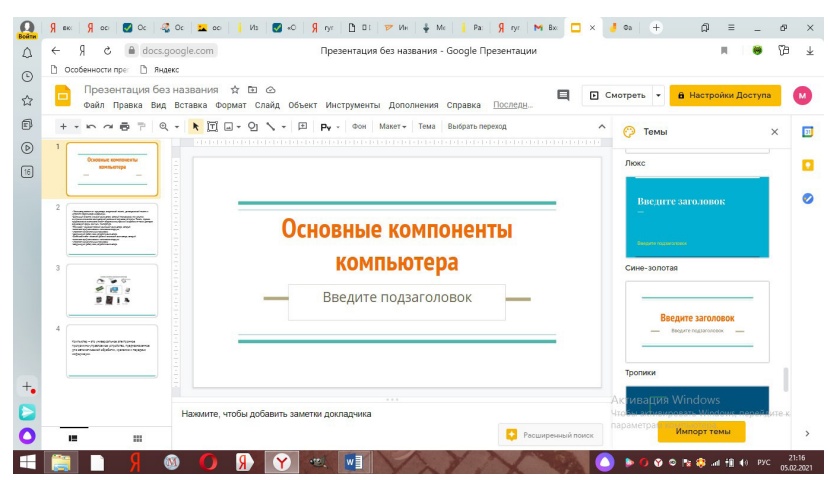

Рис. 2. Интерфейс Google Презентации

Такая работа может вестись как на уроке, так и дома. В классе учителю достаточно открыть свой диск и продемонстрировать каждую групповую презентацию, провести обсуждение полученного результата со всеми учени-ками.

Это удобно еще и тем, что все работы автоматически сохраняются у учителя. Он может корректировать их, дополнять, использовать в дальней-шей работе с другими классами.

Также можно создать тест по изучаемой теме (предоставить учащимся ссылку на тест, созданный с помощью Google Формы).

Рассмотрим на примере. Создадим тест для 9 класса по теме «Всемирная паутина». Ссылка на тест: https://docs. google.com/forms/d/e/1FAIpQLScml36zPNpD4hjYojJem8vL5v LL5UN8IhQiFkNEDBAeKgIVHg/viewform? usp=sf_link

Данный тест рассчитан на 3 минуты. После выполнения каждому учени-ку выставляются баллы, а учитель имеет возможность просмотра ответов.
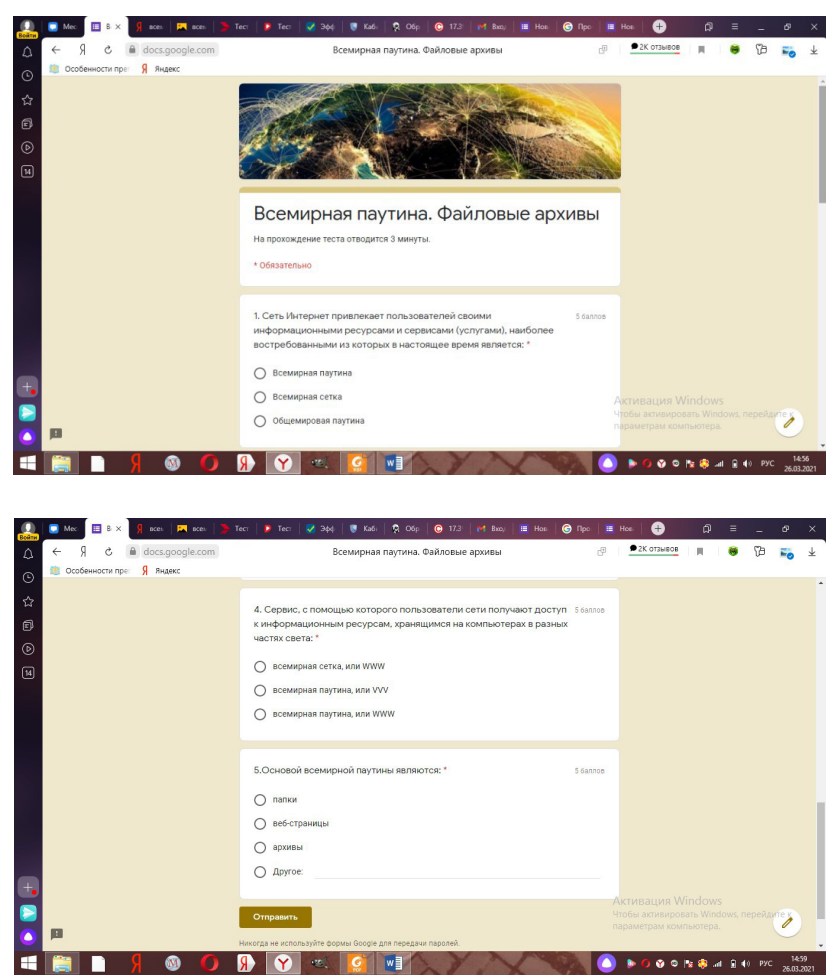

Рис. 3. Тест «Всемирная паутина» 


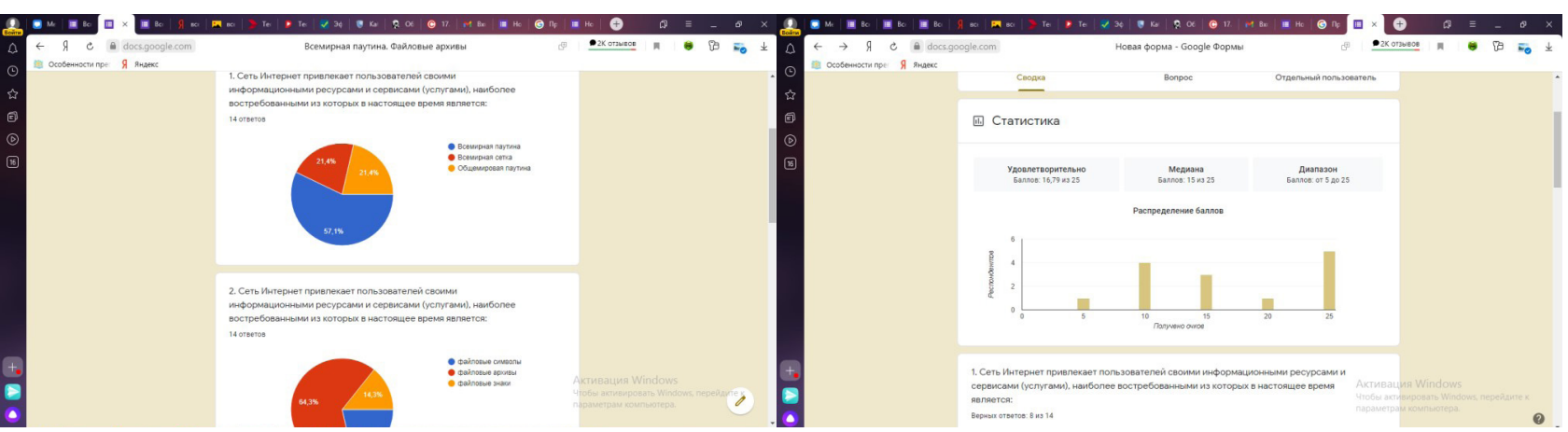

Рис. 4. Анализ результатов тестирования

С помощью контроля может быть установлена степень усвоения матери-ала: запоминание прочитанного в учебнике, услышанного на уроке, узнан-ного при самостоятельной работе, на практическом занятии и воспроизведе-ние знаний при тестировании.

Технология работы с использованием «облачного» сервиса GoogleDocs предполагает получение следующих результатов:

- предметные результаты: к ним можно будет отнести получение опыта использования информационных ресурсов и средств коммуникации в учеб-ной и практической деятельности;

- личностные результаты: развитие креативного мышле- ния, приобре-тение умения создавать и поддерживать индивидуальную информационную среду и умения работать в группе;

- метапредметные результаты: понимания взаимосвязи информатики и других учебных дисциплин.

Информационные услуги привлекают все больше внимания к их приме-нению участниками образовательного процесса в своей учебной деятельно-сти. На данный момент времени облачные технологии уже являются неотъ-емлемой частью каждого человека. Поэтому будет целесообразно вести об-лачные технологии в образовательный процесс. Исходя из этого, можно сде-лать вывод, что информационные и коммуникационные технологии будут служить хорошим средством повышения эффективности процесса обучения.

\section{Литература}

1. Ратушная Е.А. Облачные Вычисления: Новые Технологии В Образовании / Е.А. Ратушная, В.А. Ковальчук // Международный студенческий научный вестник. - 2014. - №1 [Электронный ресурс]. - Режим доступа: http:// eduherald.ru/ru/article/view?id=11820 (дата обращения: 16.04.2021).

2. Сейдаметова 3.С. Облачные сервисы в образовании / 3.С. Сейдаметова, С.Н. Сейтвелиева [Электронный ресурс]. - Режим доступа: http://ite.kspu.edu/ru/webfm_send/211 (дата обращения: 18.04.2021).

3. Ярмахов Б. Google Apps для образования / Б. Ярмахов, Л. Рождественская. - СПб.: Питер, 2015. - 224 с.

\section{References}

1. Ratushnaia, E. A., \& Koval'chuk, V. A. (2014). Oblachnye Vychisleniia: Novye Tekhnologii V Obrazovanii. Mezhdunarodnyi studencheskii nauchnyi vestnik, 1. Retrieved from http://eduherald.ru/ru/article/view?id=11820

2. Seidametova, Z. S., \& Seitvelieva, S. N. Oblachnye servisy v obrazovanii. Retrieved from http://ite.kspu.edu/ru/ webfm_send $/ 211$

3. Iarmakhov, B., \& Rozhdestvenskaia, L. (2015). Google Apps dlia obrazovaniia., 224. SPb.: Piter. 